\title{
A Study in Physical and Mechanical Properties of Hemp Fibres
}

\author{
Asim Shahzad \\ Materials Research Centre, School of Engineering, Swansea University, Swansea SA2 8PP, UK \\ Correspondence should be addressed to Asim Shahzad; mr_asim_shahzad@yahoo.com
}

Received 15 May 2013; Revised 20 July 2013; Accepted 23 July 2013

Academic Editor: S. Komarneni

Copyright (C) 2013 Asim Shahzad. This is an open access article distributed under the Creative Commons Attribution License, which permits unrestricted use, distribution, and reproduction in any medium, provided the original work is properly cited.

\begin{abstract}
This paper presents the results of the experiments undertaken to evaluate various physical and mechanical properties of hemp fibres. The study of these properties is vital for comparison with similar properties of synthetic fibres and for assessing hemp fibres' suitability for use as reinforcement in composite materials. The properties of hemp fibres were found to be good enough to be used as reinforcement in composite materials. However, the issues of relatively high moisture content of fibres, variability in fibre properties, and relatively poor fibre/matrix interfacial strength were identified as factors that can reduce the efficiency with which these fibres can be utilised.
\end{abstract}

\section{Introduction}

Hemp fibres are finding increasing use as reinforcements in composite materials, often replacing glass fibres. Found in the bast of hemp plant, these fibres have specific strength and stiffness that are comparable to those of glass fibres. The physical and mechanical properties of these fibres are still being explored.

One of these properties is the thermal degradation at elevated temperatures. Natural fibres are heterogeneous mixtures of organic materials and heat treatment at elevated temperatures can result in a variety of physical and chemical changes. The physical changes are related to enthalpy, weight, colour, strength, crystallinity, and orientation of microfibril angle [1]. The chemical changes relate to the decomposition of various chemical constituents. The decomposition onset temperature is different for different natural fibres. Thermogravimetric analysis (TGA) of jute fibres shows that they start degrading at $240^{\circ} \mathrm{C}$ [2]. For flax fibres, it has been shown [3] that degradation starts at just above $160^{\circ} \mathrm{C}$.

It has been shown [1] that thermal degradation of natural fibres generally occurs in two stages: one at $220-280^{\circ} \mathrm{C}$ temperature range and the other at $280-300^{\circ} \mathrm{C}$ range. The first range is associated with degradation of hemicellulose, whereas the second range is associated with degradation of cellulose and lignin. For hemp fibres, Prasad et al. [4] have shown that heating the fibres between $160^{\circ} \mathrm{C}$ and $260^{\circ} \mathrm{C}$ results in softening of lignin leading to opening of fibre bundles into individual fibres. The effect was more pronounced for fibres heated in air than for those in inert (nitrogen) environment.

The thermal degradation of natural fibres results in change in odour and colour and deterioration in mechanical properties of natural fibres. Sridhar et al. [5] reported 60\% reduction in tensile strength of jute fibres heated under vacuum at $300^{\circ} \mathrm{C}$ for two hours. Gonzalez and Myers [6] reported deterioration in mechanical properties of wood flour exposed to temperature range of 220 to $260^{\circ} \mathrm{C}$ for up to 68 hours. In another study, the strengths of flax and ramie fibres were found to decrease by up to $41 \%$ and $26 \%$, respectively, following heat treatment, depending on the temperature applied [7]. Wielage et al. [3] reported the tensile strength of flax fibres to decrease gradually following exposure to high temperatures for one hour. From $700 \mathrm{MPa}$ for no heat treatment, the strength was reported to decrease to $530 \mathrm{MPa}$ at $180^{\circ} \mathrm{C}, 380 \mathrm{MPa}$ at $200^{\circ} \mathrm{C}$, and $270 \mathrm{MPa}$ at $220^{\circ} \mathrm{C}$.

Attempts have been made to improve the thermal stability of natural fibres by grafting the fibres with monomers. Acrylonitrile has been successfully used in improving the thermal stability of jute [8] and sisal [9] fibres.

An important property of natural fibres is their tensile behaviour. Tensile properties of most of the natural fibres are now well documented. Perhaps the most extensive study on tensile properties of hemp fibres has been undertaken by 
Prasad and Sain [10] who used hemp fibres of varying diameters, starting from $4 \mu \mathrm{m}$ up to $800 \mu \mathrm{m}$, for tensile testing. The tensile properties were found to be clearly dependent on the diameters of the fibres, decreasing gradually with increase in fibre diameter. This is consistent with the general observation, also applicable to synthetic fibres, that as the fibre diameter decreases, the amount of flaws in the fibres also decreases, thus resulting in increase in tensile properties of fibres. Fibres of diameter $4 \mu \mathrm{m}$ had mean tensile strength and modulus values of 4200 and $180 \mathrm{GPa}$, respectively. These values decreased to $250 \mathrm{MPa}$ and $11 \mathrm{GPa}$, respectively, for fibres of diameter $66 \mu \mathrm{m}$. For the fibres of diameter $800 \mu \mathrm{m}$, the values were as low as $10 \mathrm{MPa}$ for tensile strength and $2 \mathrm{GPa}$ for tensile modulus.

Another important property to be evaluated is the surface energy of hemp fibres which is directly linked with the fibre/matrix interfacial bonding. Surface energy of a solid or liquid is a manifestation of unbalanced molecular forces at the surface [11]. Because of this imbalance, they possess additional energy at the surface. In liquids this excess energy tends to reduce the surface area to a minimum, resulting in surface tension. In solids, due to the lack of mobility at the surface, this energy is not directly observable and must be measured by indirect methods. These methods involve exposing the solid to various liquids, whose surface tensions are known, and measuring the contact angle.

Over the years, various techniques have been developed to determine the surface energies and wettability of fibres. These include sessile drop, capillary rise in a power bed or fibre assemblies, air-pressure techniques, Wilhelmy plate, sedimentation volume film rotation, inverse gas chromatography, and vapour probe techniques [12]. Wilhelmy technique has been widely used in the determination of surface energy of natural fibres and this technique has been used in this study for determining the surface energy of hemp fibres.

Wilhelmy related the downward force exerted on a vertical plate when it is brought into contact with a liquid to the contact angle between them. This method has obvious limitations for use with natural fibres because of their rough, heterogeneous, nonuniform, and absorbent surfaces. However, at the moment, this is the best method available for determining the surface energy of natural fibres.

Interfacial shear strength gives a measure of the strength of fibre/matrix bonding. Interfacial bonding is of particular concern in natural fibre composites. Natural fibre surfaces are irregular which should theoretically enhance the fibrematrix interfacial bonding. However, this is offset by chemical incompatibility between the fibre and polymer matrix. The fibres have outer waxy layer, typically 3-5 $\mu \mathrm{m}$ thick, of fatty acids which are long chain aliphatic compounds not compatible with common resins such as polyester. Natural fibres are polar in nature which also makes them incompatible with inherently nonpolar polymer matrices. This issue may be overcome by exposing the fibre surface to physical and chemical treatments to make them more compatible with polymer matrices.

In order to get a measure of the strength of fibre/matrix interfacial bonding, standard tests have been devised. Four methods are generally used for measuring the interfacial strength [13]: pull-out, microtension, microcompression, and fragmentation. The pull-out method has been found to be the best from the point of view of understanding how the interface affects composite properties and this method has been used in determining the interfacial shear strength of hemp fibres in polyester resin in this study.

\section{Materials and Methods}

Nonwoven randomly oriented short hemp fibre mat, provided by JB Plant Fibres Ltd., UK, was used. Figure 1 shows a closeup of the hemp fibre mat used.

2.1. Heat Treatment. Hemp fibre mats of size $250 \mathrm{~mm} \times$ $200 \mathrm{~mm}$ were heat treated in oven for 30 minutes. Three different temperatures were used: $100^{\circ} \mathrm{C}, 150^{\circ} \mathrm{C}$, and $200^{\circ} \mathrm{C}$. A treatment time of 30 minutes was selected because it was sufficient to remove most of the moisture from the fibres. Also keeping the fibres in an oven for longer periods of time may not be economically viable in a commercial operation.

2.2. Surface Energy. For determining the surface properties (surface energy and dynamic contact angle) of hemp fibres, a KSV Sigma 700 Tensiometer was used. It is a modular high performance computer-controlled tensiometer which can be used for the measurement of various surface properties. The machine used Win Sigma software for recording and analysing the data.

For measuring the contact, angle two liquids, one polar and one nonpolar, with known surface tension have to be used. For this experiment hexane and water were used. A sample of hemp fibre approximately $20 \mathrm{~mm}$ long was cut and hung on the balance hook of the machine by using a tape such that the fibre was perpendicular to the surface of the liquid. The vessel containing the test liquid was placed on the stage. The fibre was immersed in the liquid for a depth of up to $10 \mathrm{~mm}$ and taken out. As the fibre was immersed, the software recorded the force during advancing and the receding parts of the cycle. The fibre movement speed was $5 \mathrm{~mm} / \mathrm{min}$. The data for the first $1 \mathrm{~mm}$ of immersion was ignored. As the test progressed, the software measured the force per wetted length $(F / L)$ and force per unit wetted length minus buoyancy correction $(F / L-B)$ where buoyancy $B$ was calculated by using volume of the fibre immersed and the liquid density. The equation for measuring contact angle $\theta$ is given by

$$
\theta=\cos ^{-1}\left(\frac{F / L-B}{\gamma P}\right),
$$

where $\gamma$ is the surface tension of the liquid and $P$ is the perimeter of the fibre. The test was repeated for both hexane and water.

Since hexane is a nonpolar liquid, its contact angle gave the dispersive component of the surface energy of the hemp fibre by the following equation:

$$
\gamma_{S}^{d}=\frac{\gamma_{L}^{d}(1+\cos \theta)^{2}}{4},
$$




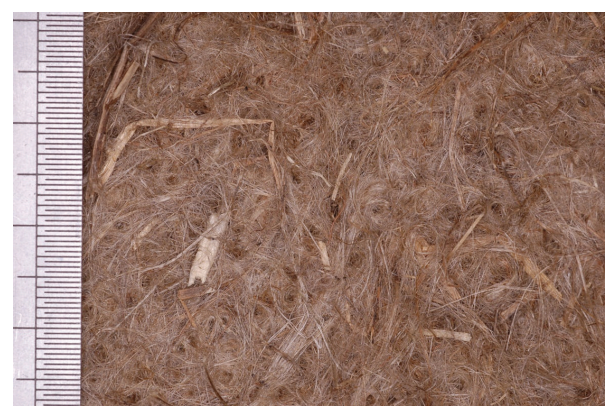

FIgURE 1: A closeup of hemp fibre mat.

where $\gamma_{S}^{d}$ is the dispersive component of hemp fibre surface energy and $\gamma_{L}^{d}$ is the surface energy of hexane, given by $18.4 \mathrm{~mJ} / \mathrm{m}$. Immersion of hemp fibre in water then helped to find the polar component of the surface energy of hemp fibre by using equation

$$
\gamma_{L}(1+\cos \theta)=2\left[\left(\gamma_{S}^{d} \gamma_{L}^{d}\right)^{1 / 2}+\left(\gamma_{S}^{P} \gamma_{L}^{P}\right)^{1 / 2}\right]
$$

where $\gamma_{L}$ is the surface energy of water and $\theta$ is the contact angle of water. Every term in this equation is known except polar component of surface energy of hemp fibre, $\gamma_{S}^{P}$, which can then be calculated. The total surface energy of hemp fibre is then the sum of dispersive and polar components of surface energy.

2.3. Thermal Characterisation. Thermal characterisation of hemp fibres was carried out by using a PerkinElmer Simultaneous Thermal Analyser 6000. The machine gave simultaneous measurement and analysis of weight change and heat flow with the increase in temperature. The machine used "Pyris" software for recording and analysing the data. Nitrogen gas was used as inert atmosphere.

Hemp fibres of weight approximately $12 \mathrm{mg}$ were placed in the sample holder and the machine was started. The temperature was increased at a rate of $10^{\circ} \mathrm{C}$ per minute. The flow rate of nitrogen gas was $20 \mathrm{~mL}$ per minute. As the temperature increased the software recorded the changes in weight and heat flow in hemp fibres. The test was stopped at a temperature of $450^{\circ} \mathrm{C}$.

2.4. Tensile Properties. The tensile testing of single hemp fibres was carried out as per ASTM D3379-75, standard tensile test method for tensile properties for high modulus single filament materials. Hemp strands were taken from different parts of the mat and elementary hemp fibres were separated from the strand by hands. The fibres were mounted on paper cards of dimensions $45 \mathrm{~mm} \times 20 \mathrm{~mm}$. Holes of diameter $11 \mathrm{~mm}$ were punched in the centre of the cards and the fibres were mounted on the cards by gluing with epoxy adhesive. Care was taken to mount the fibres in the exact centre of the holes. It was also made sure that each card contained only one fibre. Mounted fibres were inspected in a Reichert Jung MeF3 optical microscope with an Olympus E330 camera attached. Average widths of the fibres were measured by means of a calibrated eyepiece. Five different readings of fibre width were taken along the length of the fibre and their mean value was used in the calculation of tensile properties.

Mounted fibres were placed in the grips of an Instron 1162 tensile testing machine. A load cell of $50 \mathrm{~N}$ was used to measure the force. The supporting sides of the cards were cut by a scissor just before the start of the test and the test was performed at a rate of $0.5 \mathrm{~mm} / \mathrm{min}$. Since it was not possible to use an extensometer for measuring the strain in the fibres, the fibre extension was measured from the displacement of testing machine crosshead. Average tensile properties were calculated using the results of at least 20 fibres.

2.5. Interfacial Shear Strength of Hemp/Polyester. Interfacial shear strength testing of hemp fibres in polyester resin was evaluated by single fibre pull-out test using an Instron 1162 testing machine. The method was similar to that used for determining the tensile properties, except that for mounting the fibres on cards, one side of the fibres was fixed by using epoxy and a blob of polyester resin was dropped on the other side of the fibre. After fibre pulled out of the polyester resin, the embedded length was measured by using the travelling microscope. The interfacial shear strength was then determined by using the formula

$$
\tau=\frac{F}{\pi D l}
$$

where $\tau$ is the interfacial shear strength, $F$ is the force at pullout, $D$ is the mean width of fibres, and $l$ is the embedded length of fibres. The failure rate of the fibres by breaking rather than pulling out of the resin was high. Czigány et al. [14] have pointed out the inherent drawback of using this method for natural fibres. Since the resin drop is placed on the fibre without any pressure, the resin enters the voids in the elementary fibres to a smaller extent than when the resin impregnates the fibres in compression moulding pressure. The irregular cross section of the fibres is also expected to affect the calculation of shear strength.

\section{Results and Discussion}

3.1. Thermal Properties. Hemp fibres, like all natural fibres, contain moisture because one of their primary functions is to transport moisture and nutrients to different parts of the plant. The purpose of this part of the study was to determine the weight loss behaviour of hemp fibres when kept in a desiccator and when exposed to elevated temperature and thus to determine the equilibrium moisture content of the fibres.

3.1.1. Weight Loss in a Desiccator. The weight loss behaviour of hemp fibres in a desiccator was observed by keeping a sample of hemp fibres, cut out from hemp fibre mat conditioned at $23^{\circ} \mathrm{C}$ and $50 \%$ relative humidity $(\mathrm{RH})$, in the desiccator containing the desiccant copper sulphate and recording weight changes with the passage of time. The results are shown in Figure 2. The weight loss is quite rapid initially 


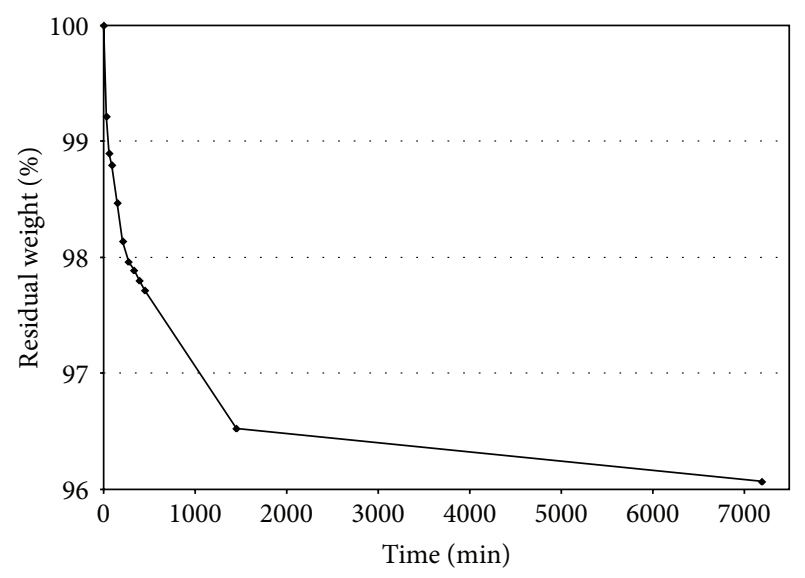

Figure 2: Weight loss of hemp fibres in a desiccator.

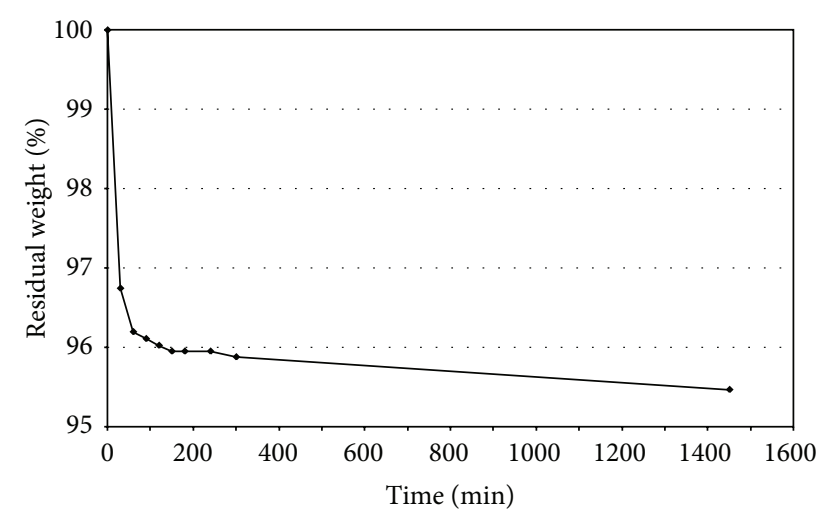

Figure 3: Weight loss of hemp fibres at $50^{\circ} \mathrm{C}$.

as the moisture in the fibres is absorbed by the desiccant but starts to stabilise after about 1500 minutes as the amount of moisture in the fibres starts to decrease. The fibres lost almost $4 \%$ of their original weight after being kept for 7200 minute (approximately five days) in the desiccator. From the graph, the fibres do not seem to have lost all of their moisture and they can be exposed to elevated temperatures to determine the weight loss behaviour and equilibrium moisture content in the fibres.

3.1.2. Elevated Temperature Weight Loss. The elevated temperature weight loss behaviour of hemp fibres was observed by keeping them in an oven at constant temperatures and recording their weight loss at different intervals of time. Four different samples of hemp fibre, each conditioned at $23^{\circ} \mathrm{C}$ and $50 \% \mathrm{RH}$, were kept in the oven at constant temperatures of $50^{\circ} \mathrm{C}, 100^{\circ} \mathrm{C}, 150^{\circ} \mathrm{C}$, and $200^{\circ} \mathrm{C}$, and their weight loss behaviour against time was recorded. The results are shown in Figures 3-6.

For the fibres kept at $50^{\circ} \mathrm{C}$, the moisture loss is much more rapid than that in a desiccator. As shown in Figure 3, the moisture loss at $50^{\circ} \mathrm{C}$ starts to stabilise after about 200 minutes, when the fibres have lost almost $4 \%$ of the moisture, as the amount of moisture in the fibres starts to decrease. After about 1500 minutes of exposure (approximately one day),

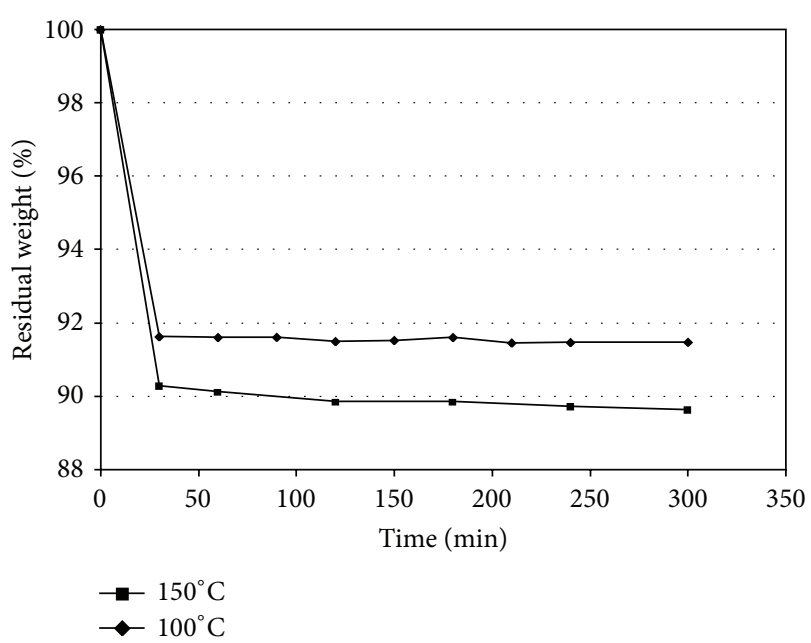

Figure 4: Comparison of weight loss of hemp fibres at $100^{\circ} \mathrm{C}$ and $150^{\circ} \mathrm{C}$.

the fibres have lost almost $4.5 \%$ of their original weight. The graph shows that exposing hemp fibres to $50^{\circ} \mathrm{C}$ does not seem to result in complete removal of moisture after 1500 minutes of exposure. So the next stage was to expose the fibres to higher temperatures to determine the equilibrium moisture content in them.

The comparison of weight retention behaviour of hemp fibres exposed to $100^{\circ} \mathrm{C}$ and $150^{\circ} \mathrm{C}$ is shown in Figure 4 . Exposing the hemp fibres to higher temperatures results in increase in the amount and rate of weight loss. It is clear that the fibres have lost most of their equilibrium moisture content within 30 minutes of exposure at $100^{\circ} \mathrm{C}$ and $150^{\circ} \mathrm{C}$. The amount of moisture lost stabilised to an equilibrium value that was different for both temperatures. The fibres exposed to $100^{\circ} \mathrm{C}$ lost about $8.3 \%$ of their initial weight after 300 minutes of exposure, whereas the fibres exposed to $150^{\circ} \mathrm{C}$ lost about $10.2 \%$ of their initial weight after 300 minutes of exposure.

A similar loss in moisture was reported by Gassan and Bledzki [15] for jute fibres dried in vacuum furnace. The fibres lost about $8 \%$ of moisture within the first 45 minutes of exposure at $100^{\circ} \mathrm{C}$. The loss of moisture stabilised thereafter and remained constant at around $9 \%$ for exposure of up to 240 minutes.

The weight loss behaviour of hemp fibres exposed to $200^{\circ} \mathrm{C}$ is shown in Figure 5. The behaviour of hemp fibres exposed to $200^{\circ} \mathrm{C}$ is significantly different because between $150^{\circ} \mathrm{C}$ and $200^{\circ} \mathrm{C}$ thermal degradation of hemp fibres starts which involves physical and chemical changes within the fibres. It has been shown [4] that heating hemp fibres above $160^{\circ} \mathrm{C}$ results in softening of lignin, the binding material in the fibres. Therefore, the weight loss at this temperature is a combination of the weight loss of moisture plus weight loss due to thermal degradation. The thermal degradation of fibres was evidenced in release of soot and blackening of the colour of hemp fibres due to oxidation. The fibres lost almost $13 \%$ of their initial weight after 180 minutes of exposure at $200^{\circ} \mathrm{C}$. The continual decrease in residual weight shows that although the fibres have lost almost all of their moisture, they 


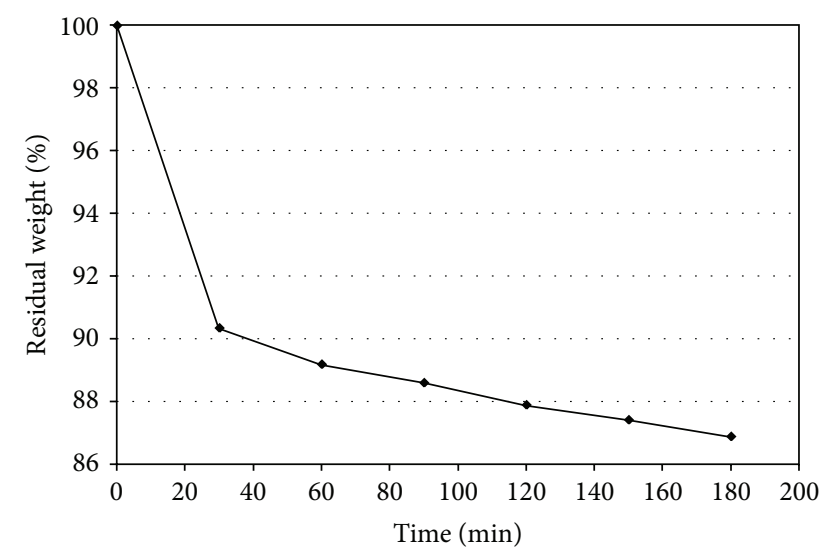

Figure 5: Weight loss of hemp fibres at $200^{\circ} \mathrm{C}$.

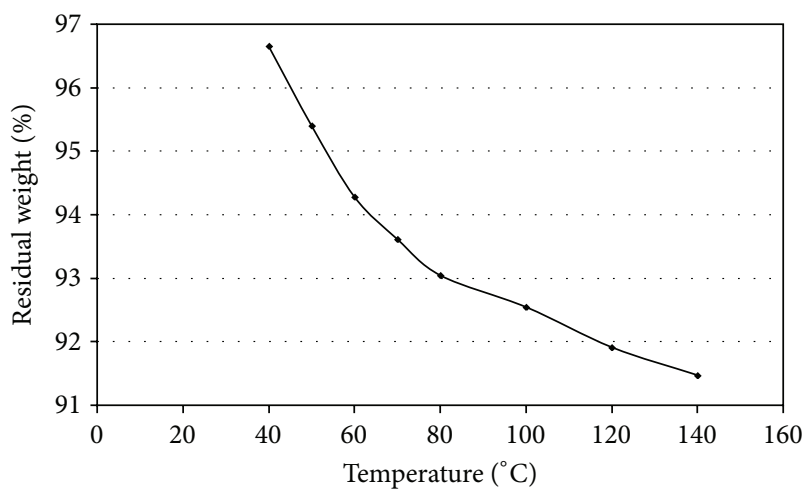

FIgURE 6: Weight loss of hemp fibres, for one hour dwell time, at increasing temperatures.

continue losing weight due to thermal degradation of the fibres.

Then a new experiment was set up whereby a hemp fibre sample, conditioned at $23^{\circ} \mathrm{C}$ and $50 \% \mathrm{RH}$, was kept in the furnace at increasing temperatures, starting at $40^{\circ} \mathrm{C}$ up to $140^{\circ} \mathrm{C}$ (in $10^{\circ} \mathrm{C}$ intervals) for a dwell time of one hour and the weight change in the sample was recorded. The dwell time of one hour was chosen because, as shown in Figures 3 and 4 , the fibres were close to their equilibrium weight after heat treatment of about one hour at a particular temperature. The resulting graph is shown in Figure 6.

The graph shows that keeping the hemp fibres at increased temperatures for one hour each results in gradual moisture loss of fibres. At $140^{\circ} \mathrm{C}$, the fibres have lost almost all (9\%) of their initial moisture which is consistent with the previous results.

These results showed that the hemp fibres had equilibrium moisture content of about $10 \%$ when kept at standard conditions of $23^{\circ} \mathrm{C}$ and $50 \% \mathrm{RH}$. This is consistent with the amount of equilibrium moisture content in hemp fibres reported by other authors $[16,17]$. Hemp fibres begin to degrade thermally between temperature range of $150-200^{\circ} \mathrm{C}$. Therefore, any heat treatment of these fibres should be restricted to about $150^{\circ} \mathrm{C}$.

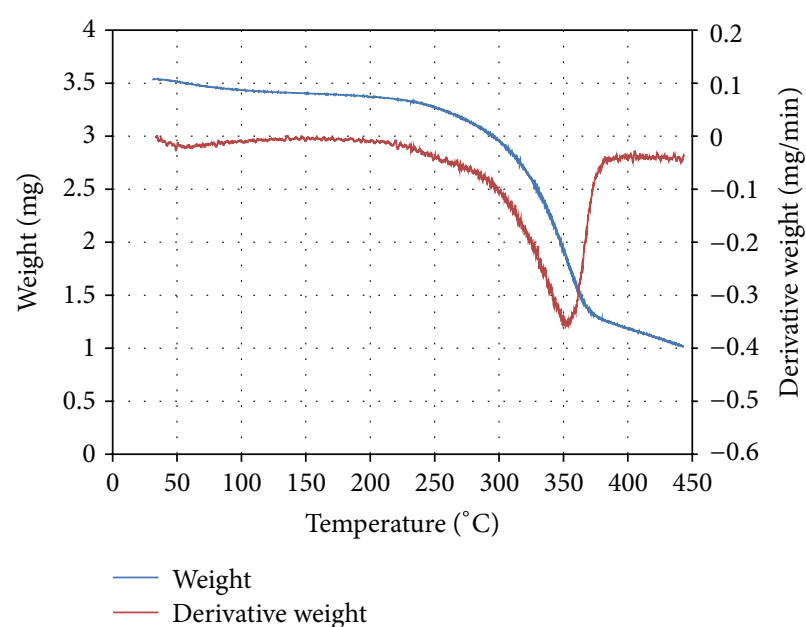

FIGURE 7: Weight loss curves of hemp fibres with increase in temperature.

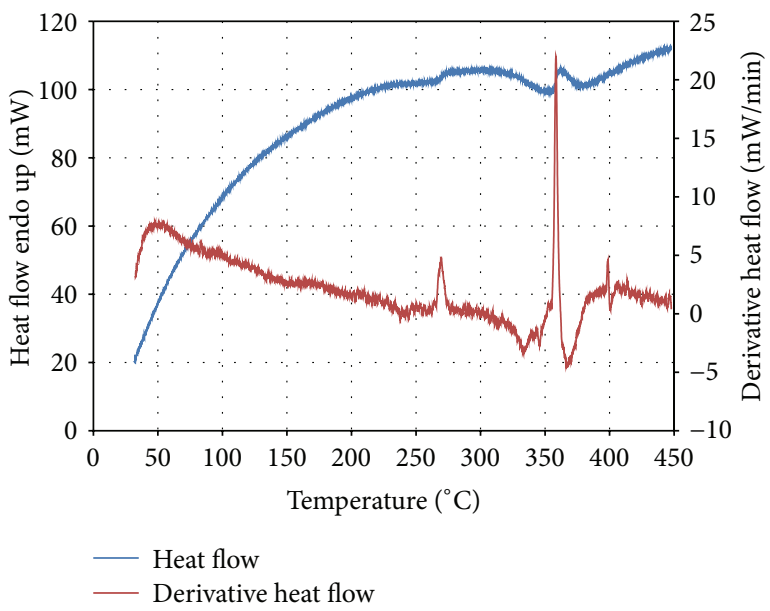

FIGURE 8: Heat flow curves of hemp fibres with increase in temperature.

3.1.3. Thermal Degradation at Elevated Temperatures. Thermogravimetric analysis is being increasingly used to understand thermal behaviour of natural fibres because it gives an accurate measure of thermal stability of natural fibres. Figure 7 shows the weight loss and differential weight loss curves for hemp fibres with the increase in temperature. It shows that thermal degradation of hemp fibres starts at around $150-200^{\circ} \mathrm{C}$ and becomes rapid at around $250^{\circ} \mathrm{C}$. In their studies on thermal degradation of hemp fibres, Backermann and Pickering [18] reported the degradation onset temperature to be $205^{\circ} \mathrm{C}$. On the derivative weight loss curve, the main peak occurred at around $360^{\circ} \mathrm{C}$ which can be associated with the degradation of cellulose. This was also confirmed in the heat flow curves shown in Figure 8.

Figure 8 shows heat flow and derivative heat flow curves of hemp fibres with increase in temperature. The derivative heat flow curve shows an initial peak at about $50^{\circ} \mathrm{C}$ which corresponds to mass loss of moisture. The second peak at about $270^{\circ} \mathrm{C}$ may be attributed to the decomposition of 
hemicellulose or pectin. The third peak at about $360^{\circ} \mathrm{C}$ may be attributed to cellulose decomposition and it again corresponds well with the peak in derivative weight loss curve in Figure 7. The small peak at around $400^{\circ} \mathrm{C}$ may be attributed to oxidative degradation of charred residue.

From their studies on thermal degradation of hemp fibres, Oujai and Shanks [19] reported the similar four peaks to exist in differential heat flow curves. The temperature corresponding to these four peaks were 50-160, 250-320, 390400 , and $420^{\circ} \mathrm{C}$. From their studies on thermal properties of hemp fibres, Troedec et al. [20] reported the temperature corresponding to degradation of hemicellulose and pectin to be $320-370^{\circ} \mathrm{C}$ and for degradation of cellulose to be $390-$ $420^{\circ} \mathrm{C}$.

3.2. Tensile Properties. The determination of tensile properties of hemp fibres is vital because it gives a measure of how much improvement in mechanical properties can be expected when the fibres are incorporated in a polymer matrix. The sensitivity of hemp fibres to moisture content has been underlined in the above experiments. The variation in moisture content can affect the tensile properties of fibres. Therefore, the fibres tested for tensile properties were equilibrated at $23^{\circ} \mathrm{C}$ and $50 \%$ relative humidity (RH) before the testing.

Evaluation of tensile properties of natural fibres is not straightforward because of the variable crosssection of fibres. Scanning electron microscope image of crosssection of one such fibre used in this study is shown in Figure 9(a). From the figure, it is clear that what appears as a single fibre to the naked eye is in fact a bundle of fibres, consisting of a number of ultimate fibres or cells, five or six in this case. This arrangement of cells makes the crosssection of fibre bundle more polygonal than circular, also shown in Figure 9(b). For this particular fibre bundle, the average cross section was found to be $20 \mu \mathrm{m}$ by $80 \mu \mathrm{m}$. The loose fibres, shown in Figures $9(\mathrm{c})$ and $9(\mathrm{~d})$, also make it clear that the crosssection of almost all the fibres is polygonal. A similar polygonal cross section has been shown to exist for flax fibres [21] which are also bast fibres like hemp. Therefore, taking the average width of the fibres and using it as average diameter can give erroneous results for evaluation of tensile properties of fibres.

Therefore, two different kinds of dimension measurements were used for calculation of tensile properties. In the first, five different measurements of width were taken along the length of fibre bundle and their average was used, assuming that it approximated the average diameter of the fibre bundle. In the second, the maximum and the minimum values of the width were used, assuming that they approximated the breadth and width of the polygonal crosssection of the fibre bundle. Table 1 shows the results for tensile properties for both kinds of crosssections considered. The mean width of the fibres (circular dimension) was calculated to be $67 \pm 26 \mu \mathrm{m}$. The figures in parentheses are standard deviations. These values are lower than those of glass fibres but still good enough to be used as reinforcement in composite materials. Any section of hemp fibre mat will contain fibre of varying cross section and hence different tensile properties. Some of the lower width fibres are expected to approach the tensile properties of glass fibres, as shown by Prasad and Sain [10]. These values are in good agreement with the values for hemp fibres reported by them at fibre diameter of $66 \mu \mathrm{m}$ and $250 \mathrm{MPa}$ and $11 \mathrm{GPa}$ for tensile strength and tensile modulus, respectively.

The calculations showed that, fortunately, the difference in properties for both types of calculations is only about $10 \%$. It is difficult to say which method is more accurate than the other. The variability in tensile properties is evident from the large values of standard deviation, again something to be expected for natural fibres. The calculation of strain did not take into account the compliance within the machine which tends to overcalculate the strain and hence undercalculate the modulus of the fibres. Silva et al. [22] showed from their studies on tensile testing of sisal fibres that taking machine compliance into consideration results in higher values of tensile modulus than the values calculated without taking machine compliance into account.

Despite the dependence of tensile properties on the width of the fibres, most of the authors fail to mention the width at which the fibre tensile properties were calculated. Also, most of the authors cite fibre diameter as the principal dimension, although what they actually mean is fibre width.

The dependence of fibre strength on fibre width was observed for fibres used for tensile testing in this study as shown in Figure 10. Fibre strength is inversely related to fibre width, showing that as the fibre width, and hence the number of flaws in the fibre, increases, fibre strength decreases.

The typical stress-strain curve of hemp fibre in tensile testing is shown in Figure 11. The curve was found to be almost linear during the whole test. Pickering et al. [23] have reported considerable variation in stress-strain curves for hemp fibres in tensile testing, with some of the fibres showing strain hardening and plastic flow as well as linear elastic behaviour. In this research all the fibres tested showed approximately linear elastic behaviour.

3.3. Surface Energy. A total of five fibres were used for evaluation of surface energy. For comparison, surface energy of chopped strand mat (CSM) glass fibres was also evaluated. Table 2 gives the surface energy of fibres in terms of their polar and dispersive components. The figures in parentheses are standard deviations.

The surface energy of hemp fibres is quite similar to that of unsaturated polyester resin, $35 \mathrm{~mJ} / \mathrm{m}^{2}$ [24]. The value of surface energy of hemp fibres is similar to the one reported by other researchers. Baltazar-y-Jimenez and Bismarck [25] determined surface tension of hemp fibre to be $31 \mathrm{~mJ} / \mathrm{m}^{2}$. Gulati and Sain [26] determined dispersive component of the surface energy of hemp fibres at $40^{\circ} \mathrm{C}$ to be $38 \mathrm{~mJ} / \mathrm{m}^{2}$ by using inverse gas chromatography. For unsaturated polyester resin, this value was $40 \mathrm{~mJ} / \mathrm{m}^{2}$. Park et al. [27] determined surface energies of hemp fibre by using Wilhelmy plate technique. The polar and dispersive components were determined to be 15.2 and $20.0 \mathrm{~mJ} / \mathrm{m}^{2}$, respectively, for total surface energy of $35.2 \mathrm{~mJ} / \mathrm{m}^{2}$. For jute fibres, these values were found to be 8.8 , 20.7 , and $29.5 \mathrm{~mJ} / \mathrm{m}^{2}$, respectively. Van de Velde and Kiekens [28] used the same technique to determine surface energy 


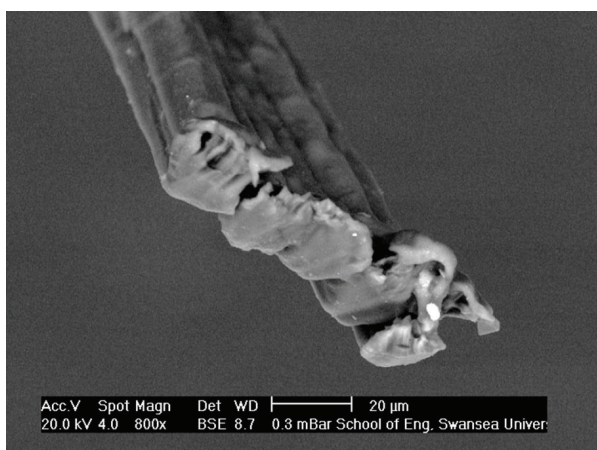

(a)

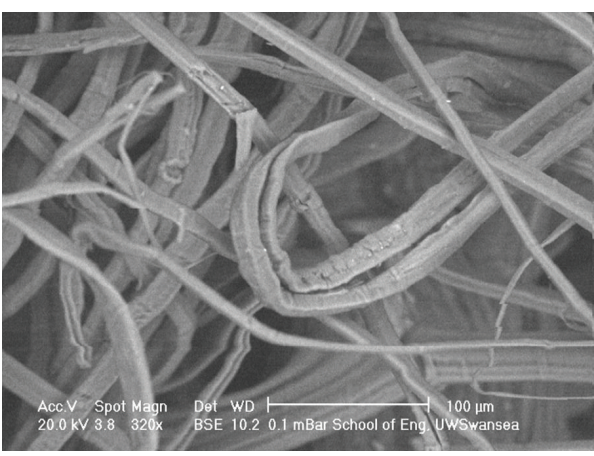

(c)

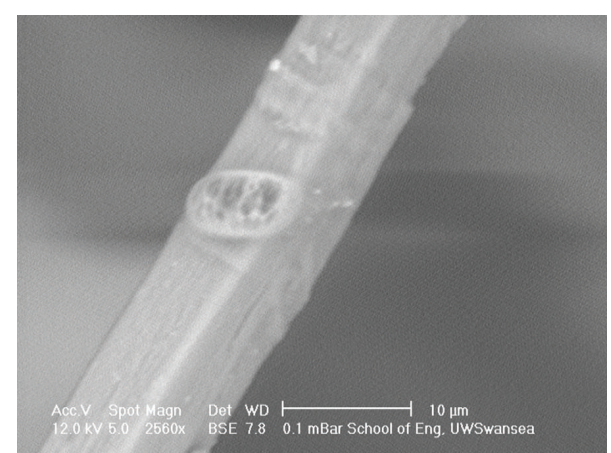

(b)

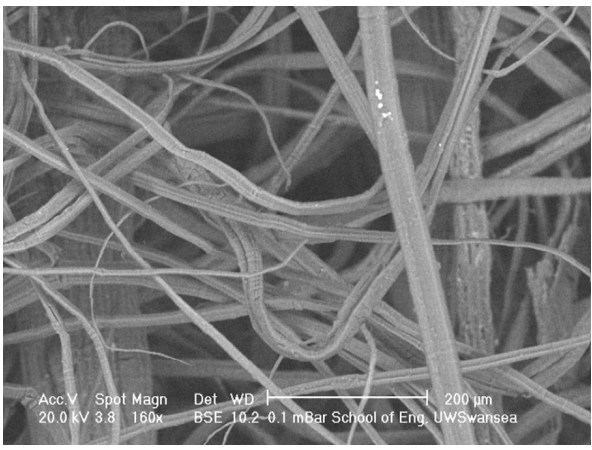

(d)

FiguRE 9: SEM micrographs of a hemp fibre bundle, (a) and (b), and loose fibres, (c) and (d).

TABLE 1: Tensile properties of hemp fibres.

\begin{tabular}{lccc}
\hline Fibre crosssection & $\begin{array}{c}\text { Strength } \\
(\mathrm{MPa})\end{array}$ & $\begin{array}{c}\text { Modulus } \\
(\mathrm{GPa})\end{array}$ & $\begin{array}{c}\text { Strain to failure } \\
(\%)\end{array}$ \\
\hline Circular & $277(191)$ & $9.5(5.7)$ & $2.3(0.8)$ \\
Polygonal & $244(196)$ & $8.6(5.9)$ & $2.3(0.8)$ \\
\hline
\end{tabular}

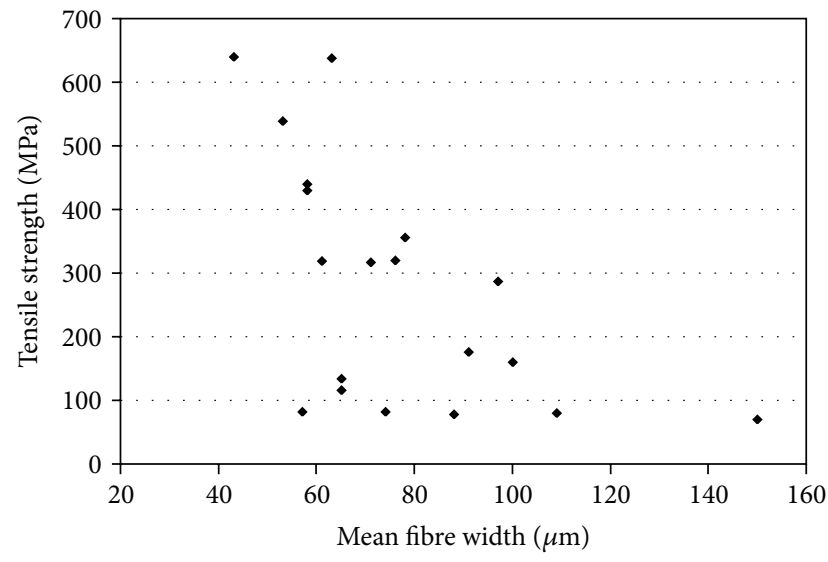

FIGURE 10: Variability of hemp fibre strength against fibre width.

of flax and glass fibres. The maximum surface energy for flax fibre was found to be $36 \mathrm{~mJ} / \mathrm{m}^{2}$. The maximum value of surface energy for glass fibres was found to be $41.64 \mathrm{~mJ} / \mathrm{m}^{2}$.

Good fibre/matrix interfacial bonding is favoured when the fibre surface energy greatly exceeds the matrix surface

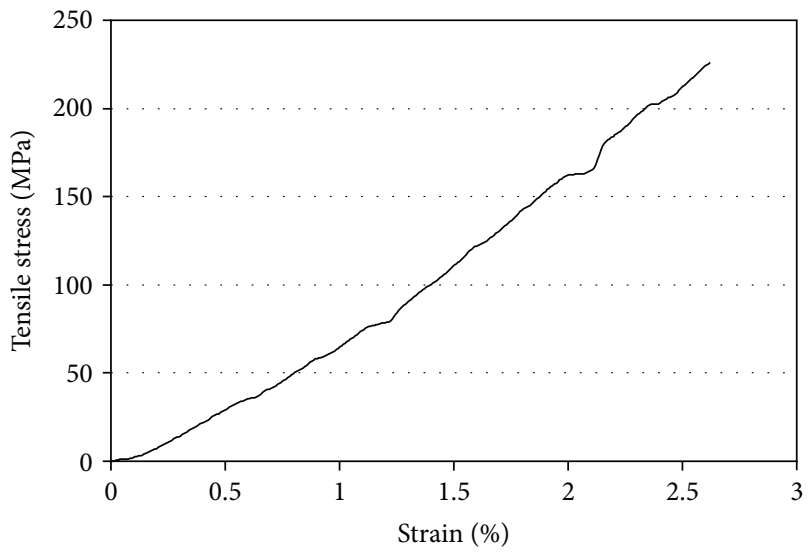

FIGURE 11: Stress-strain curve of hemp fibre in tensile testing.

energy. The similar values of surface energies of hemp fibre and unsaturated polyester resin imply that a relatively poor interfacial bonding between them can be expected. The polar component of surface energy is greater than the dispersive component, which is consistent with the polar nature of hemp 
TABLE 2: Surface energy $\left(\mathrm{mJ} / \mathrm{m}^{2}\right)$ of hemp and glass fibres.

\begin{tabular}{lccc}
\hline & Polar & Dispersive & Total \\
\hline Hemp & $20.58(4.83)$ & $12.25(6.57)$ & $32.82(4.38)$ \\
Glass & $18.44(6.45)$ & $3.05(1.88)$ & $21.49(7.63)$ \\
\hline
\end{tabular}

fibres. This polar nature will also be an impediment in good interfacial bonding with a nonpolar polymer matrix. The quantitative measure of fibre/matrix interfacial bonding is the interfacial shear strength which was evaluated next.

3.4. Interfacial Shear Strength of Hemp Polyester. Interfacial shear strength (IFSS) is another important measure of the fibre/matrix interfacial bonding. The interfacial shear strength of hemp fibres in unsaturated polyester resin was evaluated in single fibre pull-out test and the results are shown in Table 3. At least 20 fibres were used for testing and the numbers in parentheses are standard deviations.

It has been pointed out [29] that the nonuniform diameter of natural fibres may yield unreliable results for IFSS by using this method, as is evidenced by the large scatter in results (high standard deviations). Therefore, any values obtained by using this method should be seen as an approximate measure of the interfacial shear strength rather than highly accurate values.

This value of interfacial shear strength is consistent with the value reported by other authors for natural fibres in polymer matrix. Czigány et al. [14] determined the interfacial shear strength of hemp fibre (mean diameter $113 \mu \mathrm{m}$ ) in polypropylene to be $5.1 \pm 1.4 \mathrm{MPa}$, in biodegradable MaterBi polymer to be $2.9 \pm 0.9 \mathrm{MPa}$, and in biodegradable PuraSorb polymer to be $11.3 \pm 3.4 \mathrm{MPa}$. Baltazar-y-Jimenez et al. [30] reported interfacial shear strength of $8.4 \pm 1.8 \mathrm{MPa}$ for hemp fibres in cellulose-acetate-butyrate matrix. Hill and Abdul-Khalil [31] reported interfacial shear strength of $1.39 \pm$ $0.37 \mathrm{MPa}$ for oil palm fibres in polyester resin and $1.48 \pm$ $0.32 \mathrm{MPa}$ for coir fibres in polyester resin. Sanadi et al. [32] reported interfacial shear strength of sunhemp/polyester to be $4.34 \mathrm{MPa}$.

There is a range of interfacial shear strength values for glass fibres in polyester resin reported in the literature. One study [13] reports IFSS values of 10 and $12 \mathrm{MPa}$ for coated glass fibres in polyester resin. Considering these values, the IFSS of hemp fibres in polyester resin is considerably lower, which is not surprising taking into account their incompatibility with the polymer resins.

\section{Conclusions}

Various physical and mechanical properties of hemp fibres were evaluated to assess their suitability for use as reinforcement in composite materials. The moisture content of hemp fibres equilibrated at $23^{\circ} \mathrm{C}$ and $50 \% \mathrm{RH}$ was found to be about $10 \%$. This high moisture content can be a major factor in relatively high void content of the composite made from these fibres. Thermal degradation of hemp fibres started at just above $150^{\circ} \mathrm{C}$. The decomposition of hemicelluloses and pectin
TABLE 3: Single fibre pull-out testing result of hemp fibre in polyester resin.

\begin{tabular}{lcc}
\hline Interfacial shear strength & $(\mathrm{MPa})$ & $1.9(1.3)$ \\
Force at pullout & $(\mathrm{N})$ & $0.12(0.07)$ \\
Width of fibres & $(\mu \mathrm{m})$ & $33(7.5)$ \\
Fibre embedded length & $(\mathrm{mm})$ & $0.68(0.24)$ \\
\hline
\end{tabular}

occurred at around $260^{\circ} \mathrm{C}$ and that of cellulose occurred at around $360^{\circ} \mathrm{C}$.

The crosssection of hemp fibres used in this research was found to be more polygonal than circular in shape. The tensile properties of hemp fibres with mean fibre width of $67 \pm 26 \mu \mathrm{m}$ were evaluated. The tensile strength was evaluated at $277 \pm 191 \mathrm{MPa}$, tensile modulus at $9.5 \pm 5.8 \mathrm{GPa}$, and strain to failure at $2.3 \pm 0.8 \%$. The large scatter in tensile properties underlined the variability in properties of hemp fibres which is one of their main weaknesses compared to synthetic fibres. The tensile properties of hemp fibres were found to be good enough to be used as reinforcement in composite materials.

The surface energy of hemp fibres was evaluated at $32.8 \mathrm{~mJ} / \mathrm{m}^{2}$, higher than that of glass fibres at $21.5 \mathrm{~mJ} / \mathrm{m}^{2}$, but lower than that of unsaturated polyester resin reported in the literature. The similarity in surface energies between hemp and polyester was expected to result in relatively poor interfacial bonding between them. This was confirmed in single fibre interfacial shear strength testing between hemp and polyester which was lower than that reported for glass fibre and polyester in the literature.

\section{Conflict of Interests}

The author declare that he has no conflict of interests.

\section{References}

[1] P. Yang and S. Kokot, "Thermal analysis of different cellulosic fabrics," Journal of Applied Polymer Science, vol. 60, no. 8, pp. 1137-1146, 1996.

[2] D. N. Saheb and J. P. Jog, "Natural fibre polymer composites: a review," Advances in Polymer Technology, vol. 18, no. 4, pp. 351363, 1999.

[3] B. Wielage, T. Lampke, G. Marx, K. Nestler, and D. Starke, "Thermogravimetric and differential scanning calorimetric analysis of natural fibres and polypropylene," Thermochimica Acta, vol. 337, no. 1-2, pp. 169-177, 1999.

[4] B. M. Prasad, M. M. Sain, and D. N. Roy, "Properties of ball milled thermally treated hemp fibers in an inert atmosphere for potential composite reinforcement," Journal of Materials Science, vol. 40, no. 16, pp. 4271-4278, 2005.

[5] M. K. Sridhar, G. Basavarajjappa, S. S. Kasturi, and N. Balsubramanian, "Thermal stability of jute fibres," Indian Journal of Fibre and Textile Research, vol. 7, pp. 87-91, 1982.

[6] C. Gonzalez and G. E. Myers, "Thermal degradation of wood fillers at the melt-processing temperatures of wood-plastic composites: effects on wood mechanical properties and production of volatiles," International Journal of Polymeric Materials, vol. 23, no. 1-2, pp. 67-85, 1993. 
[7] A. K. Bledzki and J. Gassan, "Composites reinforced with cellulose based fibres," Progress in Polymer Science, vol. 24, no. 2, pp. 221-274, 1996.

[8] S. Patnaik, S. Sarangi, A. K. Mohanty, and B. C. Singh, "Graft copolymerization of acrylonitrile onto jute fibers (Studies on Ce(IV)-hippuric acid redox system)," Journal of Applied Polymer Science, vol. 37, no. 8, pp. 1171-1181, 1989.

[9] M. W. Sabaa, "Thermal degradation behaviour of sisal fibers grafted with various vinyl monomers," Polymer Degradation and Stability, vol. 32, no. 2, pp. 209-218, 1991.

[10] B. M. Prasad and M. M. Sain, "Mechanical properties of thermally treated hemp fibers in inert atmosphere for potential composite reinforcement," Materials Research Innovations, vol. 7, no. 4, pp. 231-238, 2003.

[11] D. W. van Krevelen, Properties of Polymers, Elsevier, New York, NY, USA, 3rd edition, 1997.

[12] J. Y. Y. Heng, D. F. Pearse, F. Thielmann, T. Lampke, and A. Bismarck, "Methods to determine surface energies of natural fibres: a review," Composite Interfaces, vol. 14, no. 7-9, pp. 581604, 2007.

[13] M. R. Piggott, "Interface properties and their influence on fibrereinforced polymers," in Composite Applications: The Role of Matrix, Fibre and Interface, T. L. Vigo and B. J. Kinzing, Eds., pp. 221-265, VCH Publishers, New York, NY, USA, 1992.

[14] T. Czigány, B. Morlin, and Z. Mezey, "Interfacial adhesion in fully and partially biodegradable polymer composites examined with microdroplet test and acoustic emission," Composite Interfaces, vol. 14, no. 7-9, pp. 869-878, 2007.

[15] J. Gassan and A. K. Bledzki, "Einfluß von haftvermittlern auf das feuchteverhalten naturfaserverst rkter kunststoffe," Die Angewandte Makromolekulare Chemie, vol. 236, pp. 129-138, 1996.

[16] B. M. Prasad, M. M. Sain, and D. N. Roy, "Structure property correlation of thermally treated hemp fiber," Macromolecular Materials and Engineering, vol. 289, no. 6, pp. 581-592, 2004.

[17] M. Sain and S. Panthapulakkal, "Green fibre thermoplastic composites," in Green Composites, C. Baillie, Ed., pp. 181-206, Woodhead Publishing, Cambridge, UK, 2004.

[18] G. W. Beckermann and K. L. Pickering, "Engineering and evaluation of hemp fibre reinforced polypropylene composites: fibre treatment and matrix modification," Composites A, vol. 39, no. 6, pp. 979-988, 2008.

[19] S. Ouajai and R. A. Shanks, "Composition, structure and thermal degradation of hemp cellulose after chemical treatments," Polymer Degradation and Stability, vol. 89, no. 2, pp. 327-335, 2005.

[20] M. Le Troedec, D. Sedan, C. Peyratout et al., "Influence of various chemical treatments on the composition and structure of hemp fibres," Composites A, vol. 39, no. 3, pp. 514-522, 2008.

[21] B. Madsen, "Properties and processing," in Proceedings of the Bio-Composites: The Next Generation of Composites, Shawbury, UK, September 2008.

[22] F. D. A. Silva, N. Chawla, and R. D. D. T. Filho, "Tensile behavior of high performance natural (sisal) fibers," Composites Science and Technology, vol. 68, no. 15-16, pp. 3438-3443, 2008.

[23] K. L. Pickering, G. W. Beckermann, S. N. Alam, and N. J. Foreman, "Optimising industrial hemp fibre for composites," Composites A, vol. 38, no. 2, pp. 461-468, 2007.

[24] D. Hull and T. W. Clyne, An Introduction to Composite Materials, Cambridge University Press, New York, NY, USA, 2nd edition, 1996.
[25] A. Baltazar-y-Jimenez and A. Bismarck, "Wetting behaviour, moisture up-take and electrokinetic properties of lignocellulosic fibres," Cellulose, vol. 14, no. 2, pp. 115-127, 2007.

[26] D. Gulati and M. Sain, "Surface characteristics of untreated and modified hemp fibers," Polymer Engineering and Science, vol. 46, no. 3, pp. 269-273, 2006.

[27] J. Park, S. T. Quang, B. Hwang, and K. L. DeVries, "Interfacial evaluation of modified Jute and Hemp fibers/polypropylene (PP)-maleic anhydride polypropylene copolymers (PP-MAPP) composites using micromechanical technique and nondestructive acoustic emission," Composites Science and Technology, vol. 66, no. 15, pp. 2686-2699, 2006.

[28] K. van de Velde and P. Kiekens, "Wettability of natural fibres used as reinforcement for composites," Angewandte Makromolekulare Chemie, vol. 272, pp. 87-93, 1999.

[29] N. E. Zafeiropoulos, "On the use of single fibre composites testing to characterise the interface in natural fibre composites," Composite Interfaces, vol. 14, no. 7-9, pp. 807-820, 2007.

[30] A. Baltazar-y-Jimenez, M. Bistritz, E. Schulz, and A. Bismarck, "Atmospheric air pressure plasma treatment of lignocellulosic fibres: impact on mechanical properties and adhesion to cellulose acetate butyrate," Composites Science and Technology, vol. 68, no. 1, pp. 215-227, 2008.

[31] C. S. A. Hill and H. P. S. Abdul-Khalil, "Effect of fibre treatments on mechanical properties of coir or oil palm fibre reinforced polyester composites," Journal of Applied Polymer Science, vol. 78, pp. 1685-1697, 2000.

[32] A. R. Sanadi, S. V. Prasad, and P. K. Rohatgi, "Sunhemp fibrereinforced polyester, part 1: analysis of tensile and impact properties," Journal of Materials Science, vol. 21, no. 12, pp. 42994304, 1986. 

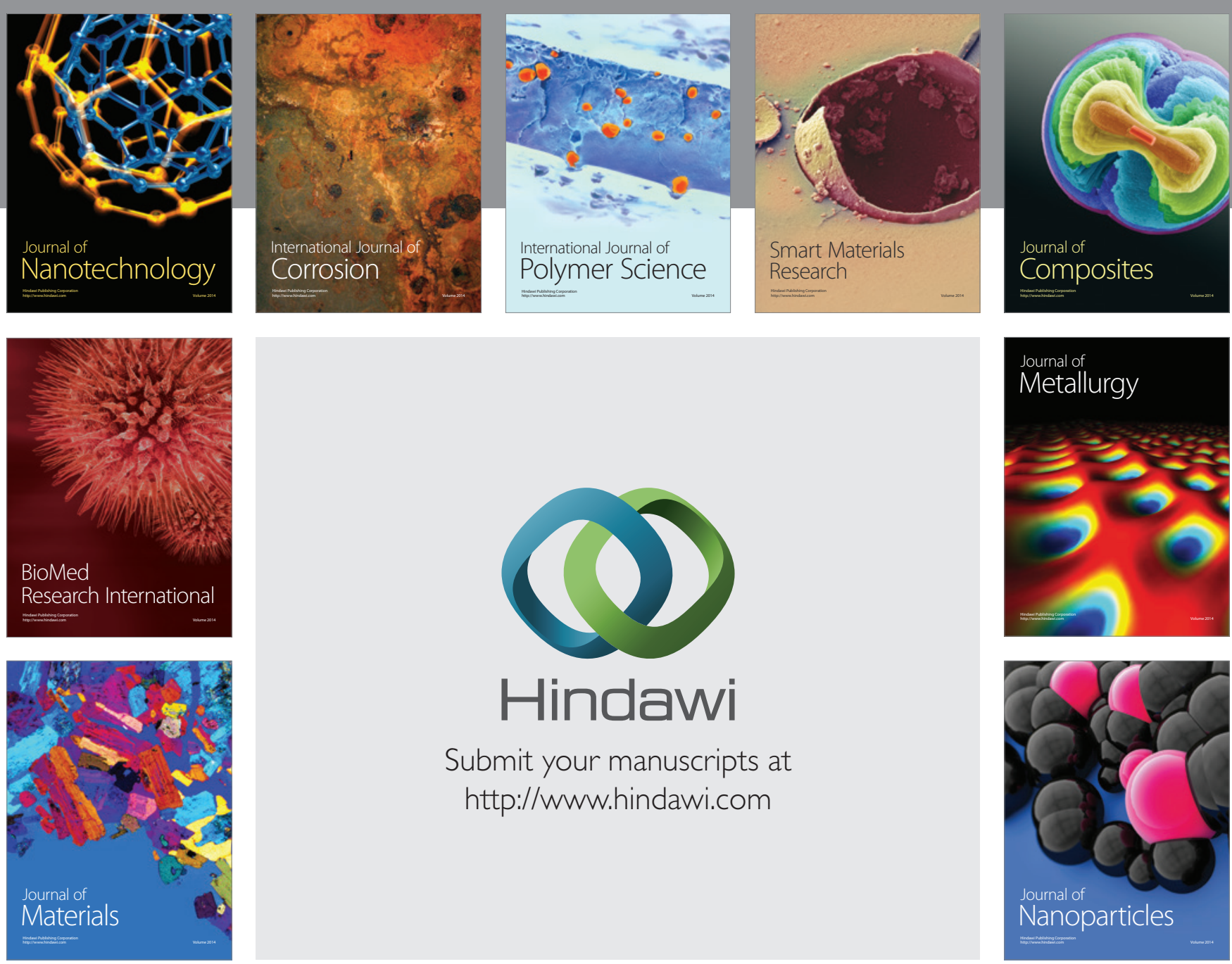

Submit your manuscripts at http://www.hindawi.com
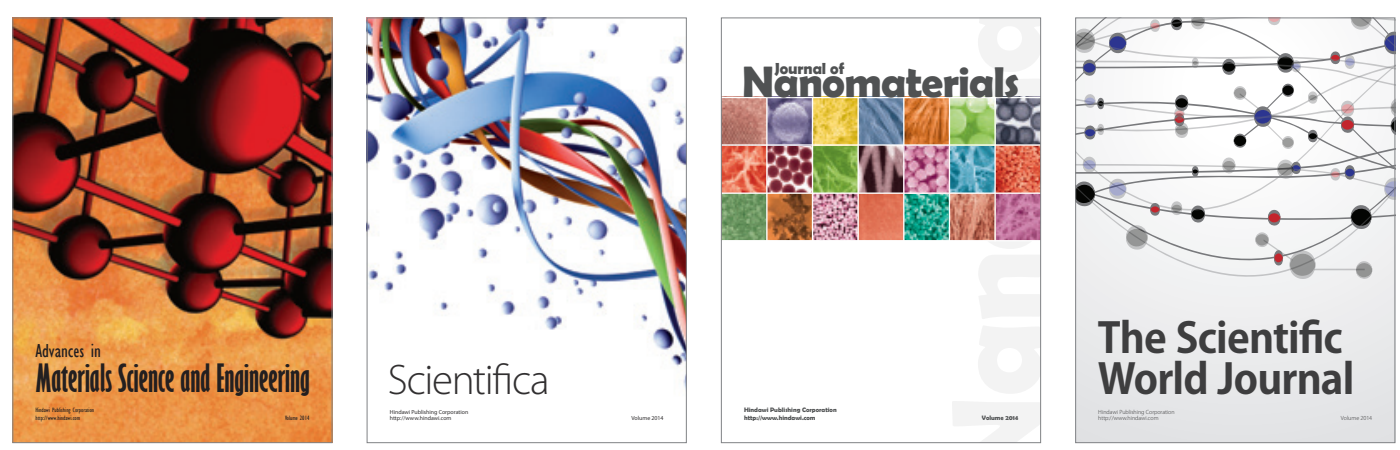

\section{The Scientific World Journal}
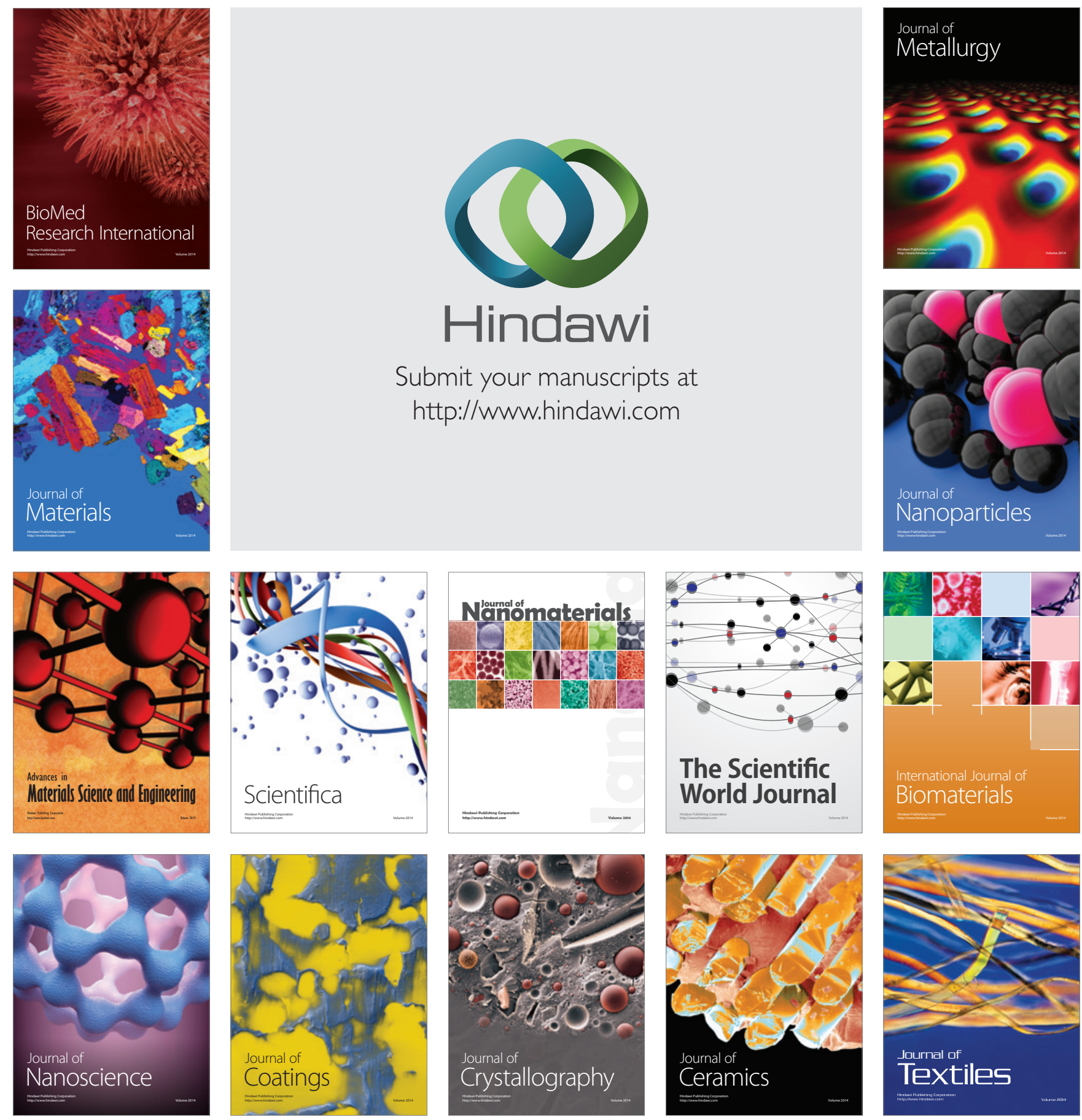